not only has no scientific merit, it also renders the report as a whole almost unreadable because it is so disjointed; and, in the absence of an analytical index (indeed, of any subject-index at all), nothing short of leafing through every one of its 666 pages will allow the reader to form any clear picture of what is happening in his own and related fields of interest.

D. G. ARNOTt

I. HIEGER

A. Levent

\title{
TEST TRACK FOR THE ROAD RESEARCH LABORATORY
}

T HE Road Research Laboratory was founded in 1933. In recent years the importance of the work being done both on road materials and methods of road construction and on traffic and safety problems has been responsible for increases both in staff and the facilities needed. The Laboratory has thus long out-grown the field at Harmondsworth on which the first buildings were erected, and various other buildings within a radius of 5 miles of Harmondsworth have been pressed into service.

The first stage in bringing all the Laboratory's activities together was accomplished on October 12, when the Laboratory's special test-track was declared ready for service. This has been built on a triangular site of some 253 acres of undulating wooded country immediately north-west of the village of Crowthorne in Berkshire. This site is ultimately to house labora. tories, workshops, offices, a library and a canteen to provide all the facilities required for the Laboratory work and to accommodate some 750 members of staff.

The new track has cost about $£ 500,000$ to build and will be used mainly for research into traffic problems and safety measures with special attention to the behaviour of vehicles at high speeds. The type of investigation proposed cannot be carried out on public roads with safety, but abandoned airfields have been used from time to time.

The track is some 3 miles long, and is built in the form of a figure of eight, one loop being about twice as large as the other; the larger loop has a steeply banked bend leading to a straight portion $900 \mathrm{yd}$. long. For tests on stability during braking at high speed a car can thus take this bend at $60 \mathrm{~m} . \mathrm{p} . \mathrm{h}$. left-handed, accelerate along the straight, which has a downhill gradient of 1 in 25, and then, while the track swings away to the left, take a siding which continues the straight portion for some $200 \mathrm{yd}$. and leads to a terminal area some $300 \mathrm{yd}$. long and $80 \mathrm{yd}$. wide. A car can thus enter the terminal area at 100 m.p.h. and be braked to a standstill in perfect safety. This area will be used for investigations of the stability of vehicles in good condition and defective when performing emergency manœuvres involving steering, accelerating and braking.

Much remains to be learnt about the steering characteristics of vehicles under transient conditions. Theory and experiment need to be closely linked in this work, and the two large paved areas afford unrivalled facilities for obtaining experimental data at fairly high speeds. One of the demonstrations during the opening inspection showed an experiment of this type. A car with unbalanced brakes entered the terminal area at high speed and spun round several times before being brought to rest. The long straight section, which has been termed the 'high speed' section, is made up of six different road surfacings for skidding experiments. A storage tank containing 54,000 gallons of water has been installed on a nearby bank with pumps and pipes so that some $800 \mathrm{yd}$. of this track can be kept wet during tests. This section of the track will thus enable investigations to be made of the effect on skidding of the texture and other properties of the wet-road surface, the properties of the tyres used and the characteristics of the vehicle as regards steering, braking and general ease of control.

The track as a whole will also be used for tests on vehicle lighting both on straight and curved roads with surfaces of different colours and textures, and also for comparison of different street lighting installations under controlled conditions, both types of test being hazardous when carried out on public roads. The track will also provide a continuous circuit where driving habits and reactions can be studied in safety : a demonstration of the technique involved was given during the opening inspection. Two cars followed each other both in wireless communication with a fixed receiving station. The experiment was to determine safe following distances; the first car carried out various manouvres, and the braking reactions, throttle position, speeds and other data involving the cars were recorded at the receiving station on a moving chart.

Where the tracks of the figure-of-eight cross, a circular centre area has been built with a diameter of $900 \mathrm{ft}$.; this is about the size of the grass area of Lords Cricket Ground. This centre area will be used to investigate large-scale problems of traffic control. Where the design of an intersection is being considered, for example, the several possible alternatives can be set up with moveable barriers and kerbs, and can be studied with actual traffic; variations in the siting and operation of traffic signals, and other aids to the flow of traffic can also be investigated.

In a complex network it may be possible to speed up the flow of traffic by a system of vehicle detectors and traffic lights controlled by a computer which adjusts the traffic controls according to the volumes of traffic signalled to it from the detector points. This central area will be available for practical tests of such systems. The track is also provided with a novel control feature. This consists of a straight wire running under the whole length, together with a series of wire loops at regular intervals. These wires can be made to emit various types of signal which can be picked up by electronic devices in the test vehicles and translated into instructions. Thus 'automatic pilots' can be used in experiments involving cars being erashed, and the loop system can be made to signal back to a driver the passage of a car over the loop in front. This system will be used to explore the possibility of providing guidance to the drivers of vehicles in dense fog. T. LONSDALE 